\title{
Reply to "a non-paternalistic value theory for occupational therapy: a response to Dige"
}

\author{
MORTEN DIGE \\ Department of Philosophy and History of Ideas, University of Aarhus, Denmark
}

Sandman points out some relevant points that certainly need further reflection. My focus will be on two interrelated points:

(1) The plausibility of the pluralist value theory that I suggest, compared with the alternative, subjectivist theory suggested by Sandman.

(2) The different ideals for professional responsibility and the relation between (OT) professionals and patients implied by these competing value theories.

Sandman makes it sound as if I am the one who defends a contentious theory whereas the alternatives, i.e. hedonistic or desire-fulfilment theories, are more uncontroversial or "minimal". I fail to see this because I find it much more straightforward to say that certain elements of a human life, e.g. accomplishment, personal relationships, and understanding, have a direct or intrinsic value and therefore are something that it is good to enjoy or desire whereas others, e.g. monotony, isolation, and confusion, have a direct or intrinsic disvalue and therefore are something that is not worth enjoying or desiring.

It is not entirely clear whether Sandman wants to challenge the view that activity is intrinsically better than passivity or the view that specific types of activities (e.g. those involving personal relationships, understanding, and accomplishment) are objectively better than others in the sense that they constitute genuine, intrinsic values.

The first point is easily misunderstood. The claim that activity is intrinsically good does not imply an ideal of hyperactivity and extreme sports. Sandman's examples of rather monotonous and mindless activities (playing Tetris and "ordering, reordering and ordering again a set of differently coloured pens") are interesting only if they more or less take up all the person's time. Most of us use a considerable amount of time on activities like that (for better or worse). It becomes a professional (OT) challenge only if the person seems incapable of enjoying or desiring anything else and I have a hard time imagining a responsible occupational therapist who would accept a life of total passivity (taking part in no challenging or social or self-involving activities whatsoever) as a possible ideal life.

The second point is a matter of considerable philosophical controversy and it would be overly ambitious to try to settle it definitively. Hence, apart from what I have said in the original article, I will just offer an example for consideration. Imagine a child in an elementary school who exclaims: "But I do not want to come to understand maths or grammar or anything else at all and I do not want to interact with you teachers and the other children and I do not want to make school work my own accomplishment!" That would certainly be a pedagogic challenge but I think it would take a lot more than this to make it a challenge to our belief in these values. On the contrary, it would simply be unprofessional if the schoolteachers reassessed their mission and value commitments to the effect that they gave up on teaching maths to those who did not want it, allowed the antisocial children to be left alone, and so on.

Quite another but very important consideration is that we sometimes have to settle for something short of the ideal. Imagine for example that the child suffers from social phobia and gets extremely anxious when

Correspondence: Department of Philosophy and History of Ideas, University of Aarhus, Denmark. E-mail: filmd@hum.au.dk 
having to interact with other people. It is obvious that the professional thing to do would not be some sort of chock therapy in which the child was forced to take part in "valuable" social activities. But again, this does not mean that we should reassess the value of social interaction and personal relationships. On the contrary, the reason why this presents us with a professional challenge (whether it is best met by pedagogues, occupational therapists, or psychologists) is exactly that this child suffers from some sort of disease or malfunction (the malfunction may not be located exclusively in the child) that cuts her/him off from central elements of a good life and typically even involves suffering in itself because of the social isolation. There are never any guarantees that such a patient can be treated or helped to the point of participating fully in personal relationships. The professional thing to do is of course to compensate as much as possible for this, e.g. by focusing on activities that the patient actually finds enjoyable. But only in extreme cases would it be best to give up the aim of meaningful personal relationships entirely. Some autistic children, for example, are able to relate emotionally to their parents only in a quite diminished way. It would be ridiculous to claim that this is not always a significant loss and that professionals should not (for fear of acting paternalistically) go to great lengths to stimulate emotional relationships as far as possible.

However, I would like once again to point out that it seems to be a dogma (and an attractive one) in occupational therapy that the goal of activity and participation should be pursued by the therapeutic means of activity and participation. The obvious reason is that valuable activities that the patient is coerced or manipulated into and that do not engage her/him are not really valuable at all. The disagreement between Sandman and me I is whether the value of the activities is constituted by such engagement alone (whether it is because the person finds pleasure in it or simply desires it).

Does occupational therapy consider occupation to be merely an instrumental value, i.e. only of value in so far as the person in question enjoys being in an active, functioning relationship with her/his environment or only in so far as this is her/his expressed desire? Well, the situation faced by occupational therapists often is exactly that the patient does not enjoy her/ his life and is not able to fulfil her/his desires. I guess there is no uniform stand in the OT profession, but my contention is that it would be a responsible presumption that such a person would in fact benefit from activity and participation and that lack of any expressed desire for this should not rule out the possibility of an unexpressed one. I realize that such second-guessing of people's "real" desires involves the risk of acting paternalistically. I just find the alternative much less attractive, because it brings the risks of professional failure and irresponsibility. It would be better to insist that such second guessing should be based on the important professional virtues of imagination, ingenuity, and respect. Paternalistic behaviour is problematic mainly when based on impersonal, standardized procedures and considerations of cost-efficiency. 